\title{
Oral Tradition as Source of Construction of History of Pre Literate Societies
}

\author{
K. VijayaKumari \\ Assistant Professor, All Saints' College, Thiruvananthapuram, Kerala, India \\ E-Mail: vijayahistory5@gmail.com
}

\begin{abstract}
Oral traditions are considered as a reliable source of historical writing. It represents collective experience and wisdom. But oral tradition is largely anonymous. It imperceptibly absorbs what comes from many sourcesindividuals, inside groups, and outside groups. In any society, oral tradition has the function of supporting the political structure, economic systems, religious aspects and the social and cultural moves of the group. The knowledge and experience of elders and lessons learned by several generations through experience are crystallized into it. In this paper, an attempt is made to analyse the importance of oral tradition, its elements and various aspects in association with utilization of oral tradition as important source material for the reconstruction of history. Paper also emphasize the need of carefulness and patience on the part of historian while using the facts and should go in to deep the roots of the oral tradition in order to ensure that the facts collected and gathered are authentic and genuine.
\end{abstract}

Keywords: Oral tradition, Cultural Development, Great Tradition

\section{INTRODUCTION}

Oral tradition has been one of the important sources in the construction of the history of but its importance has always been undermined by the dominated sources such as written sources. Oral tradition is the collection of information through the word of mouth from generation to generation. It has been the main vehicle for transmitting information in preliterate societies. Oral traditions are an important component of all cultures especially in small and isolated non-literate groups, where the framework of culture rests almost wholly on the oral tradition. Knowledge, both sacred and secular, is transmitted from generation to generation by word of mouth. Spoken word and memory play a crucial role in the transmission of the cultural heritage (Dube, 1990).

Of course, oral tradition is a reliable source of historical writing. . These are actually historical accounts that are transmitted from one generation to the next through word of mouth. They can be in the form of praise poems and songs telling of the heroic deeds of an ancestor, a clan or a whole community of people. Oral traditions, transmitted in the form of tales, myths and legends, fairytales, songs, especially epic songs and poems, proverbs, riddles and other genres, form an important treasury of many a people's cultural heritage even today. Among ethnic groups without a written tradition, almost all knowledge was conveyed orally from one generation to the next.
The Great Tradition is principally the work of the urban literate and represents abstract thinking and philosophical speculation as also creative aesthetic expression in varied forms of art. This tradition draws a wide range of elements from the little traditions. Several symbols are reinterpreted in such a manner that their philosophical content is enriched. It is essential to bear in mind that most great civilizations have had large illiterate populations who were influenced nevertheless by the small literate segment which produced the prime movers and pace-setters for cultural continuities and change. Great Tradition is creative expression in varied forms of art and principally the work of the urban literate and represents abstract thinking and philosophical speculations. They are indebted to little traditions in many ways and literate populations were influenced by the small literate segment which produced the prime movers and pace-setters for cultural continuities and change.

The oral tradition was subjected to reflection and reinterpretation where it was religious and philosophical in nature and to verification and experimentation where it dealt with more mundane problems. In the process it often got transformed. Memorization is important. Legends and myths regarding supernatural and natural phenomena also emanated from the oral tradition (Dube, 1990). Oral traditions contain cultural information about the past carefully preserved and handed down from generation to generation within a tribe.Oral tradition has been a universal form of historical consciousness, which usually operated alongside writing. Talking of ethno history, it combines the ethnographic method with the historical records. The literary tradition in its pure form remains confined to a limited segment of the society. Its reach is enhanced by cultural carriers, who can grasp some of its ideas and diffuse them to the masses after adapting them to the folk idiom.Recently, a number of efforts to bring together historians and anthropologist to collate the approaches and methods of the two fields in a fruitful collaboration in teaching and research have been made (Cohn, 1990)

\section{ORAL TRADITIONS AND CULTURAL DEVELOPMENT}

The whole human society and each group in the society can be viewed as the manifestation of the social processes between the interacting members. These interactions 
ultimately form the social structure and the norms, values and customs related with these social relationships determines the cultural aspects of human being. SomenathBhattacharje, (2016). Jan Vansina's text, Oral traditions: a study in historical methodologyis a crucial methodological intervention of how oral traditions can be an aided source in reconstructing a society with scarce written evidence. Vansina argues for the equal value of oral source of history with the written records. The sources like 'oral history' and 'oral traditions' encode the vast knowledge about the past. The goal behind collecting them is to save sources from oblivion, to come to a first assessment of the events occurred. Vansina (1965). Oral tradition, a tradition or practice that is shared orally or through speech- usually handed down from generation to generation. Oral tradition is usually eventually written down, but can tell us so much about the society and the people who originated them and allowed history to be kept and shared by groups who do or did not have writing. It was a good way to keep valuable information for others in your group and would allow the literate and the illiterate alike to share the information. Oral tradition include myths and legends which throw light on origin of communities- their social, economic and political institutions, their taboo, totems, social concepts and practices (Fadeiye, J, D, 2004).

Secondary sources available at government offices, archives, libraries, museums often complements the information collected by field work as it pieces together memories of people and what the elite have written about them. At times they fill in the gaps where the link is difficult to be found. For instance, the information collected through oral histories depends upon the extent the informants can recall (Rachel Santhosh, 2008)

\section{ELEMENTS OF ORAL TRADITION}

When thinking about oral tradition we often take into account mythology and sacred lore, legends and epics, folk songs and folk tales, and proverbs and riddles. These are important elements of the oral tradition, but they are by not the only components of it.Oral tradition is a vast reservoir of secular knowledge. Subjects as diverse as astronomy, agronomy, medicine, meteorology, and rudimentary engineering and technology are encompassed in the oral tradition. The spells and chants, sacred rituals employed to gain secular ends and other knowledge systems, traditional knowledge, knowledge about medicinal plants, treatment and others come under oral tradition. Knowledge and skills are transmitted through this tradition. Aesthetic expression and various art forms - dance, dance-drama, and dramaare vitally linked with the oral tradition. In its totality the oral tradition is a repository of culture as well as its vehicle (Dube, 1990).

There are diversified functions of folklore; the first function is to provide education to the people and a note of discipline to the very young children. These provide moral to ridicule laziness, rebelliousness snobbishness. The second function is that it serves to validate culture, justify its rituals and institutions to those who perform and observe them. The third function is, there are in every cultural word the social norms and customs have been highlighted altogether. The fourth function is, it keeps the social solidarity and social interaction in the entire community. (Somenath Bhattacharje, 2016).

Oral traditions could also be ideological and may be for the maintenance of status of dynasties, classes, cults or associations such as praise - appellations, praise-poems, ritual utterances, epic and myths of various types. Eic is a class of traditions all on its own. It is a narrative couched in poetic language, subject to special linguistic rules of focus. It is instructive about the lives of heroes and entertaining by their dramatic qualities. Tales as a type of tradition are fiction and cannot be original. Tales, often do not have a beginning, a composition and an end, but rather disappeared into later tales. Though useful for the historian they contain materials of very mixed age and parentage. Myths are called as sacred narratives telling which is another aspect of orally transmitted tradition among tribal communities. For them myths are real to which cannot be overemphasized. Many authorities on Mythology hence stressed the reality, as distinct from the fantastic or unreal aspects of myth. Myth is not merely a story that is told but a reality lived. Myth is not an idle tale rendered, but a hard worked active force behind a generation who had lived in the past. Myths, as tradition of the people, are not invented they are experienced. The important attributes of myths are that they are cultural, psychological and spiritual. Proverbs are vital aspect of oral tradition, are the repository of the collective wisdom of the tribe, tribal etiquette dictates that the older members of the society. Proverbs are efficient in placing contemporary incidents within the continuum of tribal tradition. It is an ever-growing and blossoming source of historical data. It is imperative to stress here that oral traditions are veritable tools in historical reconstruction. Many professional and non-professional historians have judiciously used oral sources in writing history.

Thus oral tradition represents the essence of their culture. It helps to understand the meanings that people themselves give and to comprehend how they define different life situations. Cognitive orientations of the people are shaped by it. It also spells out the desirable goals and values which provide them broad guidelines to chart the course of their lives. Implicit in it are the evaluative norms which determine the people's sense of right and wrong. The normative standards that sustain the social system are embedded in the corpus of knowledge and beliefs transmitted by oral traditions. In many ways it helps in the socialization processes and ensures broad conformity to the norms of culture. The economic and material base of life keeps functioning because of the known-how and skills imparted by oral tradition (Dube, 1990).

Oral tradition is largely anonymous. It represents collective experience and wisdom. It imperceptibly absorbs what 
comes from many sources-individuals, inside groups, and outside groups. The lessons learned by several generations through experience are crystallized into it. People have to respond to new challenges in new ways. The more successful of these responses get absorbed into the oral tradition.In some societies a part of the oral tradition can be extremely valuable in the reconstruction of history. Of course, not all oral tradition leads to historical reconstruction. In many societies remembered history of a few generations tends to merge into mythology. However, in many cultures there are people who remember genealogies as well as the deeds of valor and heroism of key historical figures. Thus, such parts of the oral tradition can be tapped as sources of history.

Perhaps the most important area of research in oral tradition is its role as an instrument of socialization. Through oral tradition explicit and implicit attitudes and values as well as the general outlook on life are transmitted. Cultural emphases and definition of goals of life are also determined by the oral tradition. This aspect needs to be investigated in depth. The roles of oral tradition in identity formation as identities of groups as well as of larger collectivities are influenced by the oral tradition. (Dube, 1990). In a world of global interaction, with aggressive promotion of international tourism, the exotic elements of tradition have become objects of curiosity and interest. While projecting tradition in an attractive and presentable manner leads to hybridization and even vulgarization. A comparative study of different cultural policies in this regard is essential.

In spite of the unjustifiable allegations or arguments levied against the use of oral tradition in historical writing, it is important that the historian must know the shortcomings noticeable in oral tradition. Should take care to avoid as much as possible such shortcomings while using oral tradition. The historian must understand the fact that precise dates are rare in oral tradition and that oral tradition can be distorted or fabricated to give credence to a religion or distorted for political reasons in order to glorify a set of people, clan or family. During the transmission of oral tradition from one generation to another orally makes it vulnerable to inaccuracies. But discovering the elements in oral tradition which are reliable as sources of data, which are unreliable, and which can provide clues to the locations of reliable sources elsewhere, and this task can be so frustrating as to cause the researcher to reject oral sources altogether. To get to the root of the oral traditions is important.to make conclusions authentic and worthwhile. Elements in traditions must be cross-checked with other traditions, with anthropological studies, with archeological data, with the results of linguistic methods such as glottochronology and with written records. It is not an easy job using oral traditions as a historical source. In the view of Vansina, Oral traditions constitute important primary hypothesis that have to be confirmed by independent evidence such as that uncovered by documentary or archaeological research. But with patience and care and the ability to transcend his own cultural and educational biases, the historian in Africa can make good use of oral traditions".

\section{CONCLUSION}

Even though there has been a considerable opposition to the use of oral tradition in historical writing, it is clear that such opposition is unjustified because there is no historical source either oral or written that is perfect. There is no record of fulfilling all required conditions. Nevertheless, the use of oral traditions and other non-written sources like oral history-oral evidence, archeological remains and a host of others have come to stay as reliable sources for the writing of history or for the recovery of the past history. Many eminent historians used oral sources or a non-written source to reconstruct history proves that oral traditions are good source materials for historical writing. However, it is a good practice to cross-check oral sources and derived conclusions through other available sources like written sources and also throughinterdisciplinary approach such as anthropology, ethnography, linguistics, geography, sciences and archaeology. Historian must be careful while using the facts and also to be patient to go to the roots of the oral tradition in order to ensure that the facts collected and gathered are authentic and genuine. Through the multidisciplinary method, historians are able to apply the insights of history, historical linguistics, archaeology, and the resources of other disciplines to enrich the evidence of oral traditions, oral history, and folklore. The reliability of oral tradition can be better guaranteed through critical analysis of data and by following internal and external criticism of sources. Finally, a careful effort should be made in the preservation and the enrichment of the tradition so as to preserve the authenticity and diversity of traditional cultures.

\section{REFERENCES}

[1] Dube, S.C., (1990). Tradition and Development, Delhi, Vikas Publishing House Ltd, 99-106.

[2] Report on an International Workshop in St. Augustin near Bonn, Germany, The Present-Day Importance of Oral Traditions - Their Preservation on,, Bonn, Publication, Bonn, Germany,Walther Heissig and Rudiger Schott.

[3] Cohn, B. S. (1990). An Anthropologist among the Historian and Other Essays. Delhi: Oxford University Press.

[4] SomenathBhattacharje, (2016). Interaction between great and little tradition: The dimension of Indian culture and civilization, International Journal of Research in Engineering, IT and Social Sciences, 6(5), 1-3.

[5] Vansina, J. (1965). Oral tradition: A study in Historical Methodology.Chicago, Chicago: university press, 13, 196.

[6] Fadeiye, J, D. (2004). Historiography and Methods of Teaching History for N.C.E and Undergraduates. Oyo: immaculate City Pulishers. http://.wikipedia.org,Definition of oral tradition.

[7] Rachel Santhosh, (2008). Mapping of an Ethnohistory of the Paniyan: Some Preliminary Reflections, Indian Anthropologist, 38(1), 61-76 Retrieved from http://www.jstor.org/stable/41920057, Accessed: 10.11-2018 11:49 UTC. 